\title{
The digital patterning of optical phenomena in natural gemstones and, the design deployment of interior modeling for wall molding
}

\author{
Eun-Ju Kim ${ }^{\dagger}$ \\ Dept. of the Faculty of Liberal Arts and, Academic (Interiors \& Living Formative), Dongshin University, Naju 520-714, Korea
} (Received November 29, 2011)

(Revised December 19, 2011)

(Accepted December 30, 2011)

\begin{abstract}
Absrtact Light color reaction, immersion and diffusion operation through the mural art can be expressed in a variety of image types. In this paper, the digital pattern for mural art was formed by observation of the optical phenomena in natural gems and the relation between the optical sparkle in gems and minerals and pattern design was characterized. New possibility with relevance for design work based on ultramarine with a beautiful sheen and spectrum of the coloring was used for Sustainable 3D simulation modeling and represented by high-resolution Image graphic design.
\end{abstract}

Key words Digital pattern, Optical phenomena, Interior modeling, Natural gemstones, Mural art

\section{천연 보석의 광학 현상적 digital patterning과 벽면 조형을 위한 interior modeling 으로의 design 전개}

\section{김은주}

동신대학교 교양교직(인테리어 \& 생활조형)학부, 나주, 520-714

(2011년 11월 29일 접수)

(2011년 12월 19일 심사완료)

(2011년 12월 30일 게재확정)

요 약 Mural Art는 빛의 색채 반응과 몰입, 확산 작용을 통하여 다양한 이미지를 나타내게 할 수 있는 디자인 작업이 다. 본 논문은 천연 보석의 광학 현상을 Mural Art에 적합한 Digital Pattern으로 형성하고, 보석 및 광물의 광채와 작품 디 자인과의 연관성에 대하여 고찰하였다. 작품 디자인의 상호(관련) 작용에 나타난 새로운 가능성을 광채가 아름다운 울트라 마린(Ultramarine)과 스펙트럼(Spectrum)의 색채 예술로서 벽면에 기초하여, 고해상도 Image의 그래픽 디자인으로 표현하고, 지속가능한(3D) Simulation의 Interior(Presentation) Modeling으로 활용하여 보았다.

\section{1. 서 론}

천연 보석의 광학적 특성은 가시광선과 반응하여 커팅 형태, 연마 상태, 굴절률, 결정 방향에 따라 다르게 나타 난다. 보석에 투사된 빛의 산란과 반사, 굴절에 의한 발 광 현상(Illumination-magnified $30 \times$ )은 Digital 방식의 이미지 패턴[1]으로 형성될 수 있다. 보석 내부의 불순 물이나 결정 입자를 통한 빛은 회절 또는, 서로 간섭을 일으켜 나선형의 명암을 나타내고, 산란, 굴절에 의하여 색감이 생성되며, 색을 좌우하는 주 요인은 (1) 화학조성

Corresponding author

Tel: +82-16-367-8332

E-mail: gloriaclover@hanmail.net
(2) 결정구조 (3) 불순물 등이다[2]. 본 논문에서는 하울 라이트, 오팔, 스타 사파이어, 스피넬, 레인보우 크리스 탈 등을 실험 대상으로 하여 천연 성분을 알아보았다. Super Graphic(=Rising path +Dynamic +Digital pattern) 으로 적용, 가능한 독특한 광채와 색상[3]을 연구하고, 광학 현상의 특징적 Mural Digital Pattern을 실내에 도 입하고자, 벽면 조형의 새로운 경항을 고려하였다.

\section{2. 실험방법}

전자기파 스펙트럼 $(400 ~ 1000 \mathrm{~nm})[4,5]$ 은 온도 $\left(0 \sim 50^{\circ}\right)$, 상대 습도(10 80\%)의 작업 환경에서, 1.3/2. Omega 


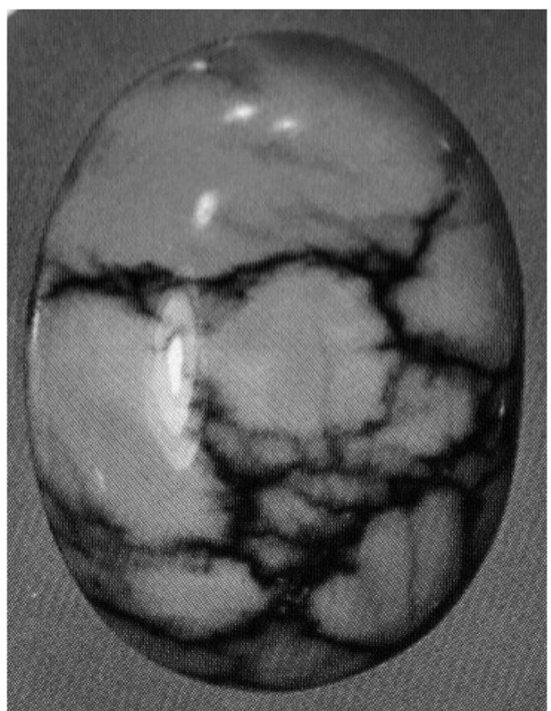

Fig. 1. Howlite.

Colorful Camera sensor CMOS 또는, 현미경 관찰을 통하 여 발견될 수 있으며, Digital Pattern과 Modeling의 요소 로서도 중요한 역할을 할 수 있다. <Art Work(1-4)>에 응 용된 천연 보석의 Image Source를 실험에서, Digital Pattern화하여 디자인과의 연관성에 대하여 논하자면[6],

(1) 하울라이트(Howlite, Fig. 1)는 주성분으로 $\mathrm{Ca}_{2} \mathrm{~B}_{5} \mathrm{SiO}_{9}$ $(\mathrm{OH})_{5}$ 을 포함하는 물질들이 표면에서, 갈철색, 암회색, 검은색의 그물망 형태처럼 분포되어 나타나며, 순수한 청색은 매우 희귀하다. 하울라이트의 메트릭스(Matrix) 구조가 보여주는 아름다운 심미적 공간미와, 황금비례 (Golden Ratio, 1:1.6)의 구성은 <Art Work.1>(Fig. 19(a))의 면적 분할에 응용될 수 있다.

(2) 썬 오팔(Sun Opal, Fig. 2)은 주로 $\mathrm{SiO}_{2} \cdot \mathrm{nH}_{2} \mathrm{O}$ 의 성분으로 구성되고 주황색을 띄지만, 입사광의 방향에 따라 발광과 청색의 섬광이 서로 섞이고 간섭되어 안개

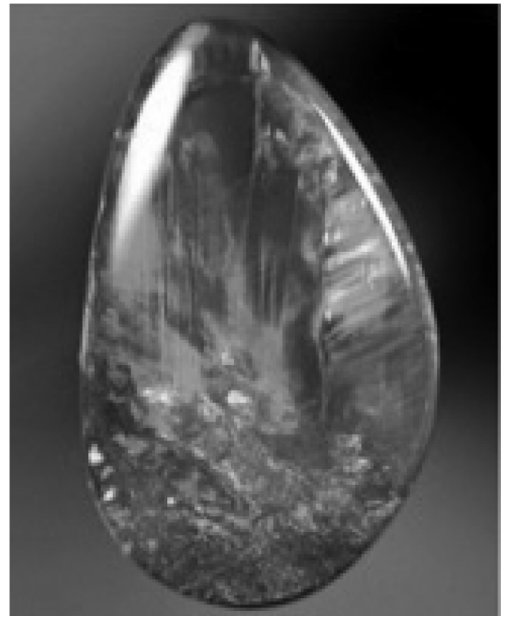

Fig. 2. Sun opal.

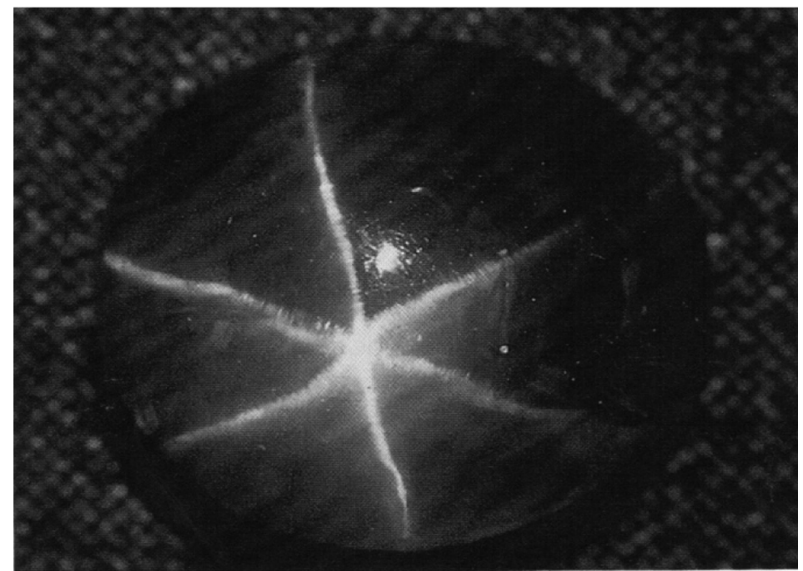

Fig. 3. Star sapphire.

처럼 희미하게 나타나 보인다. <Art Work.1>(Fig. 19(a)) 에서 베일(Veil)에 쌓인 몽환적 이미지 형성이 자연스럽 도록, 섬광의 광학적 효과를 적용하여 보았다.

(3) 스타 사파이어(Star Sapphire, Fig. 3)는 캐보션 (Cabochon) 형태로 가공할 경우, 평행하는 섬유상 결정 에 $90^{\circ}$ 로 입사한 빛이 반사하여 나타나는 샤토얀시 (Chatoyancy)현상과, 빛의 간섭으로 인하여 별 모양의 성채 효과가 나타날 수 있다. Star 성채는 육방 결정계 에 의하여 각각 $60^{\circ}$ 간격과 6 개의 방향으로 반사상을 나 타낸다[7]. 철 $(\mathrm{Fe})$ 과 티타늄 $(\mathrm{Ti})$, 바나듐 $(\mathrm{V})$ 성분에 의하 여 발색되는 보랏빛을 띈 청색을 <Art Work.1>(Fig. 19 (a))에 적용하여 회화적 안정감의 가치를 자랑하는 울 트라마린(Ultramarine)의 색감으로 구현하였다.

(4) 스피넬(Spinel, Fig. 4)은 크롬 $(\mathrm{Cr})$ 과 철 $(\mathrm{Fe})$ 을 주성 분으로 하는 미세한 팔면체의 결정이 지문처럼 배열되어 있고, 솜털 형상을 보이기도 한다. 함유물도 일정한 각도 로 배열되어 밤하늘의 은하수처럼 빛의 회절 현상이 나 타나며, <Art Work.2>(Fig. 19(b))에서 성채와 같은 갤 럭시(Galaxy) 패턴으로 응용하여 보았다.

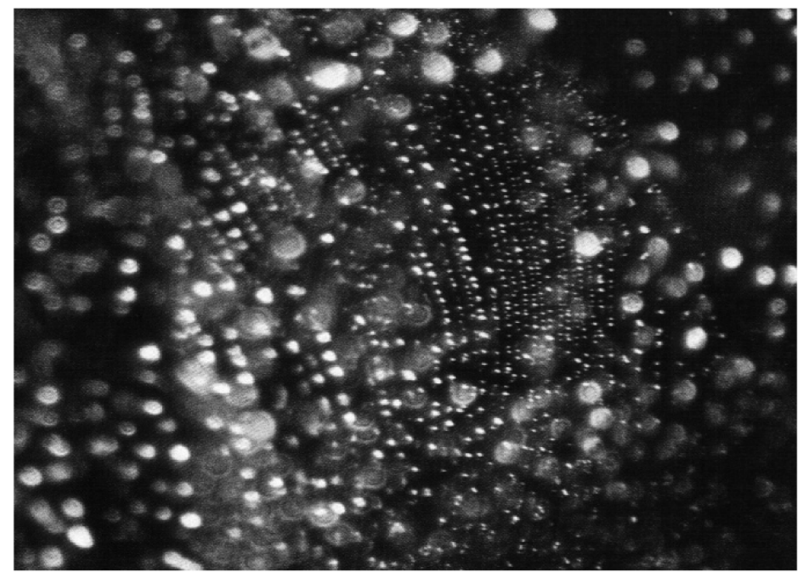

Fig. 4. Spinel. 
(5) 레인보우 크리스탈(Rainbow Crystal, Fig. 5, 6) 표면 조직의 얇은 층에서 반사되는 독특한 발광 효과는

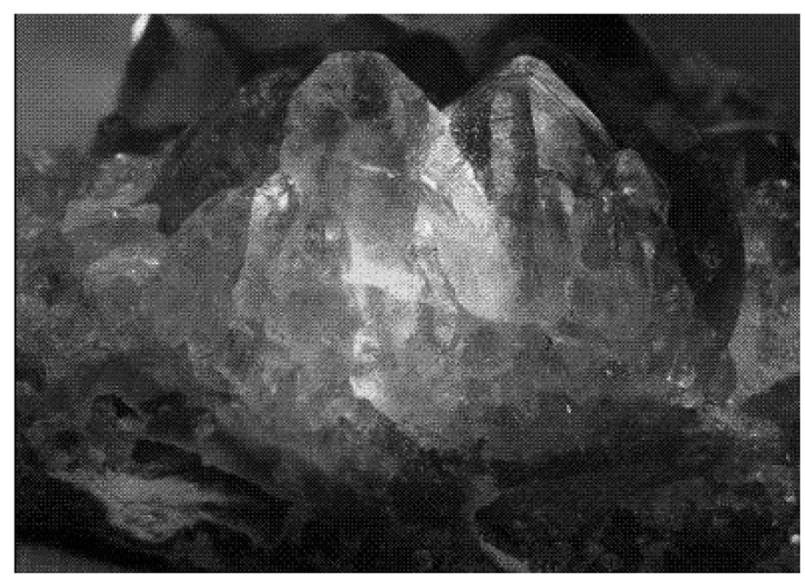

Fig. 5. Rainbow crystal (1).

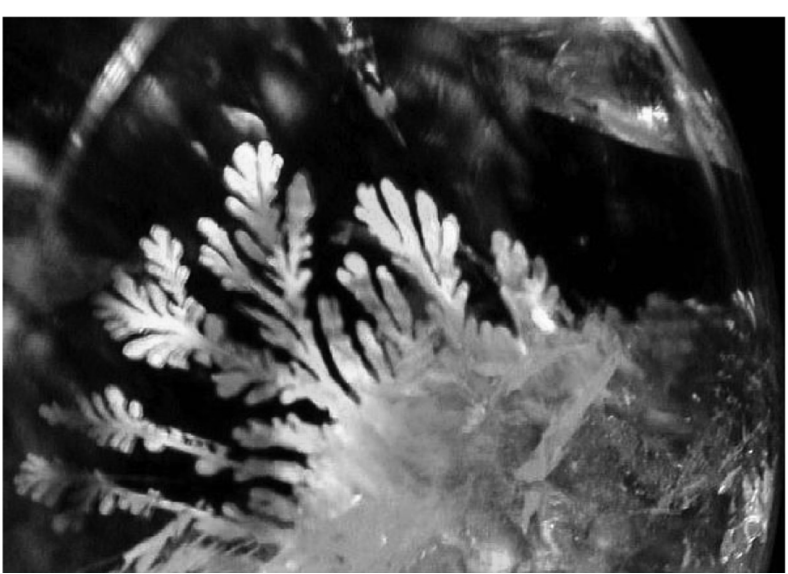

Fig. 6. Rainbow crystal (2).

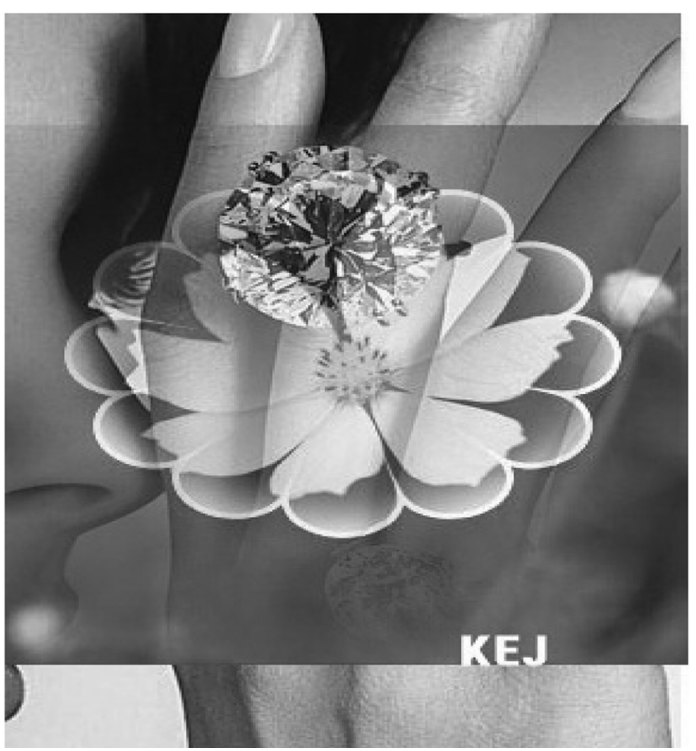

Fig. 7. Universe's stars.
휘도가 강하고 환상적인 색감을 표현한다[8]. (Fig. 19(b)) 의 <Art Work.2>에 이러한 광학 현상을 적용하여, 루미 나이트 컬러(Luminite Color)패턴처럼, 신비감을 발산하 며 아름답고 선명하게 나타나도록 하였다.

자외선 조명의 형광 반응도 어두운 곳에서 시선의 집 중력이 강하여, ‘우주의 별'(Fig. 7), 대자연과 풍경, 경 치의 표현에서 완성도 높은 실재감을 나타낸다.

또한, 대기중의 많은 물방울이 빛을 산란시켜 구름은 하얗게 보이며(Fig. 8), Light나 Self Illumination이 물 체에 적용되면, 섬광(Scintillation)의 효과가 나타난다 (Fig. 9). 백색 광선이 중첩되면 합성 간섭에 의한 Color

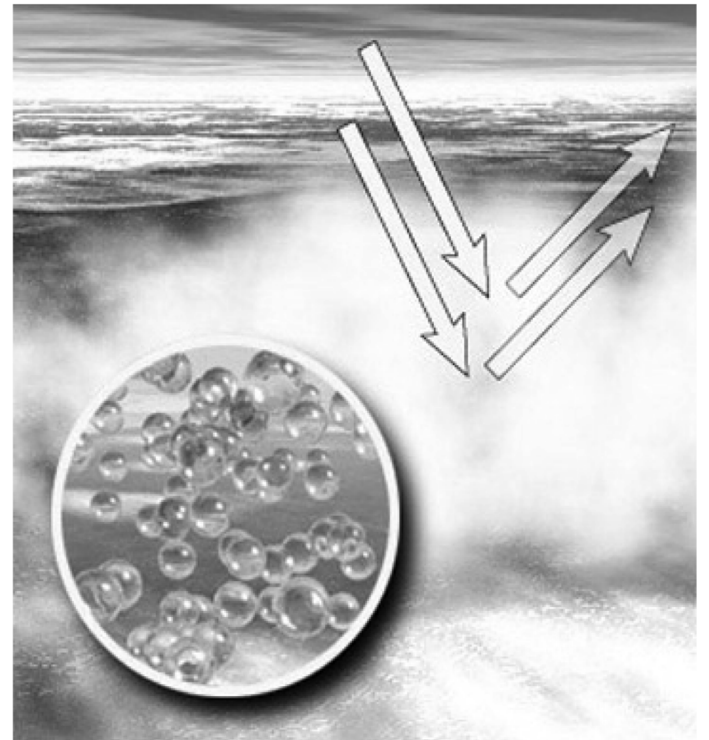

Fig. 8. The scattering of light.

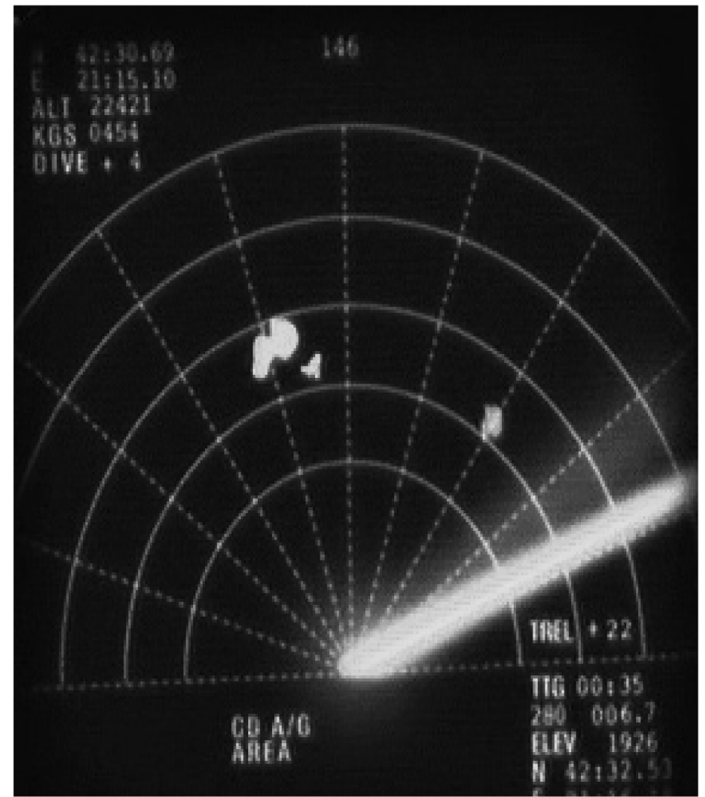

Fig. 9. Light and scintillation. 


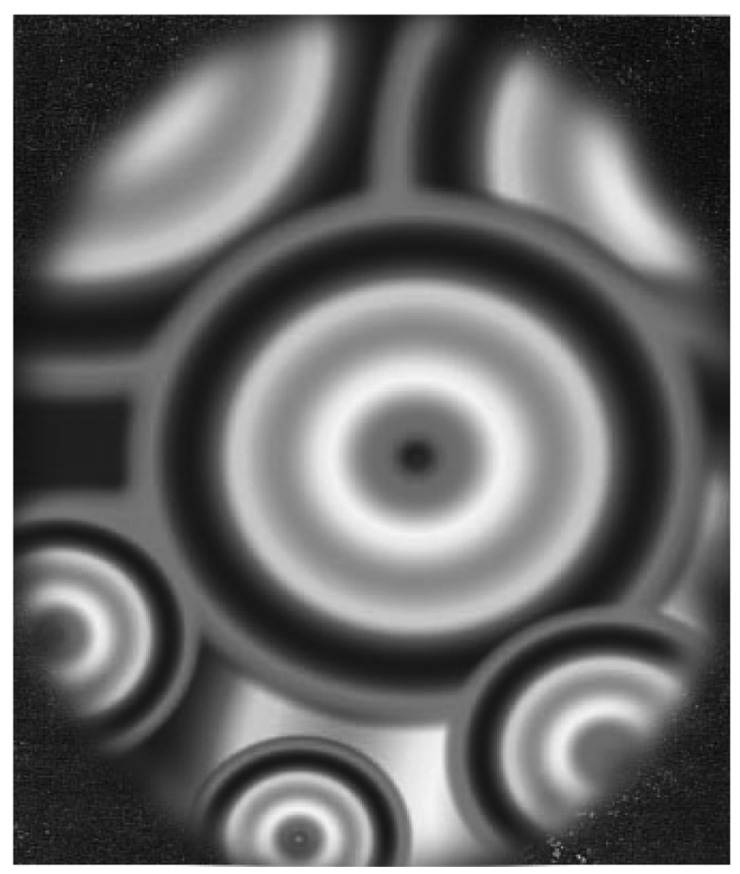

Fig. 10. Spectral colors.

Spectrum(Fig. 10)을 형성하고, 휘광을 결정하는 굴절률 은 빛의 반사로써 광학 현상이 벽면의 면적만큼 도입되 면, 결정 부분에서 그래픽으로 현상적 특성을 강조할 수 있다. 울트라마린(Ultramarine)과 스펙트럼(Spectrum) 의 색채가 자연광의 변화 또는, 보석의 광채와 함께 복합적으로 나타날 수도 있다. 주된 효과를 패턴화 하 여 벽면에 Mural 데이터 세트(Data Set)의 이미지를 표 현하고, 실내 공간의 테마(Theme)와 성립, 조화되도록 한다.

\section{Modeling}

Table 1은 서론에서 언급한 천연 보석과 광학적 현상 에 의한 연관성을 모티 브로 하여, 이미지로 표현되는 다양한 효과를 보였다. Adobe 회사의 그래픽 프로그램 을 응용하여 Digital patterning의 혁신적 상징성이 벽면

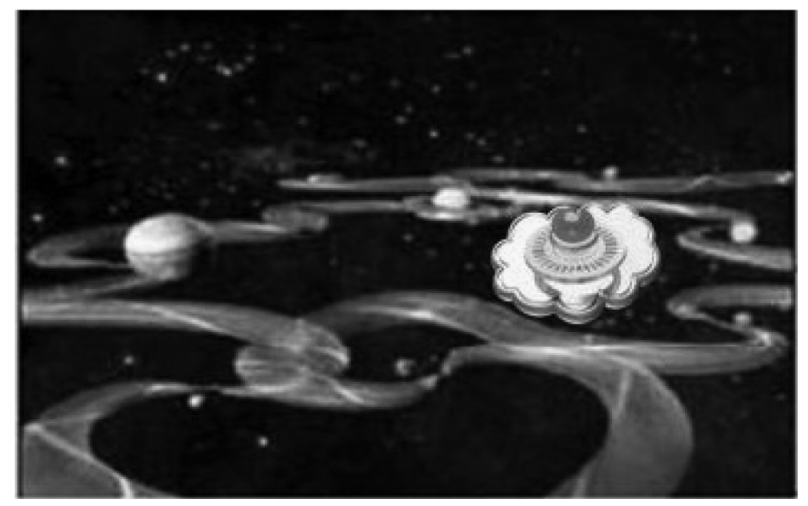

Fig. 11. The planet's orbit \& scintillation.

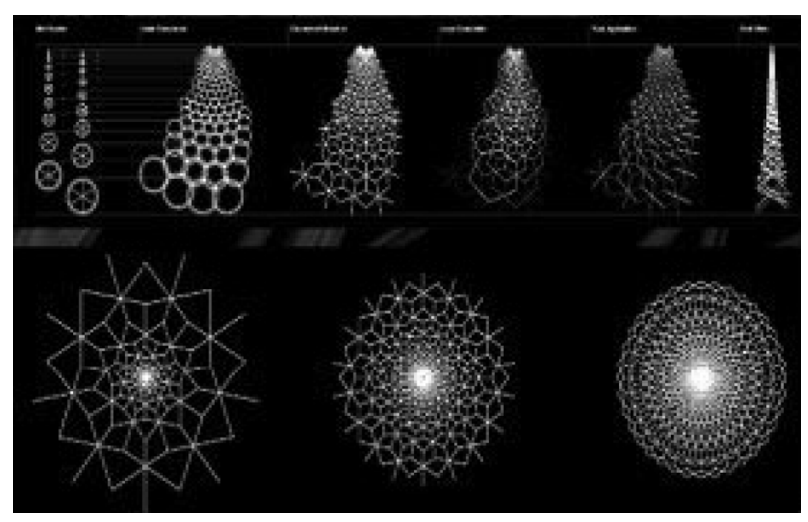

Fig. 12. The flow of light in galaxy.

조형을 위한, 풀 스케일(Full scale)의 실척 모형에 융합 되도록 하였다[9, 10].

\subsection{Mural (digital) pattern}

은하는 대규모의 무리를 지어 성벽 같은 우주 장성 (Great Wall)의 거대구조를 형성한다. 전체적으로 균일하 게 분포하는 가운데, 텅빈 공간이 드문드문 포함된 거품 구조를 이루기도 하며, Fig. 11 13에서 관찰된 별, 행성 들은 거품 방울에 위치하고 있다[11]. Table 2는 작품의 실험적인 퍼포먼스(Performance)로서 빛과 천연 보석의

Table 1

Creative motives \& image effects exhibited by optical characteristics

\begin{tabular}{lll}
\hline Optical characteristic & Creative motives & Image effects \\
\hline (1) Howlite (Matrix Structure) & (1) Cycle of Nature & (1) Visual balance \\
(2) Sun opal (-Girasol) (Play of color) & (2) Mutual relevance & (2) Visionary color \\
(3) Star sapphire (Asterism, Chatoyancy) & (3) Visual reaction & (3) The fusion of art \& philosophy \\
(4) Sapphire, spinel (Change of Color) & (4) Scientific symbolism & (4) Expectative variables \\
(5) Rainbow crystal (Luminite, Iridescence) & (5) Aesthetic experience & (5) Illusionist catharsis (Symbolize, Mythologize) \\
& (6) (3D) Formed the theme of & (6) Innovative technology \\
& space & \\
\hline
\end{tabular}




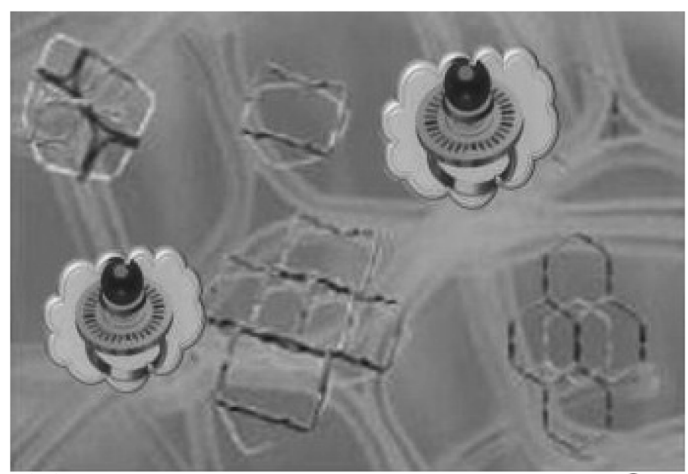

(a) Microscopic mix \& Matching (1)

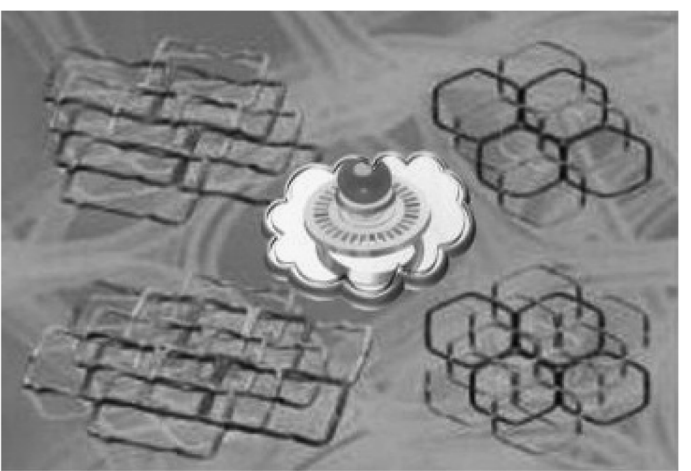

(b) Microscopic mix \& Matching (2)

Fig. 13. Analyzed illuminant and matrix image designs ( $a, b)$ of Astro.

Table 2

Concept of the works

\begin{tabular}{|c|c|c|c|c|}
\hline Title $\quad$ Mural & Motives & (Related) Images & & Coloring \\
\hline (Art work.1) & $\begin{array}{l}\text { (1) Stars } \\
\text { (2) Astro } \\
\text { (3) Planet-model (Fig. 11 13) }\end{array}$ & $\begin{array}{l}\text { Golden dew } \\
\text { (Works 1) }\end{array}$ & $\begin{array}{l}\text { (1) Picture \& Photo } \\
\text { (2) Solar light }\end{array}$ & $\begin{array}{l}\text { Ultramarine \& } \\
\text { Green }\end{array}$ \\
\hline (Art work.2) & $\begin{array}{l}\text { (1) Jewels } \\
\text { (2) Galaxy } \\
\text { (3) Planet-model (Fig. 11 15) }\end{array}$ & $\begin{array}{l}\text { Golden Ratio } \\
\text { (Works 2) }\end{array}$ & $\begin{array}{l}\text { (1) Photo } \\
\text { (2) A ray of Light }\end{array}$ & $\begin{array}{l}\text { Spectrum } \\
\text { \& White }\end{array}$ \\
\hline
\end{tabular}

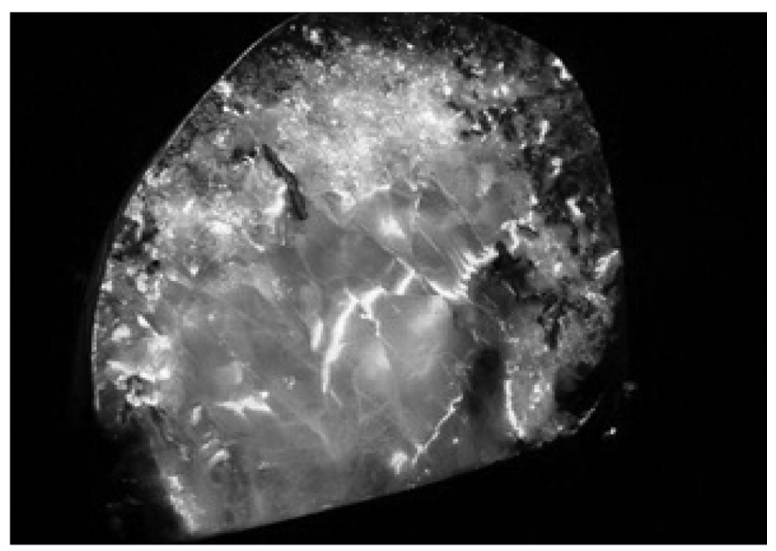

Fig. 14. Colorful iridescent star opal.

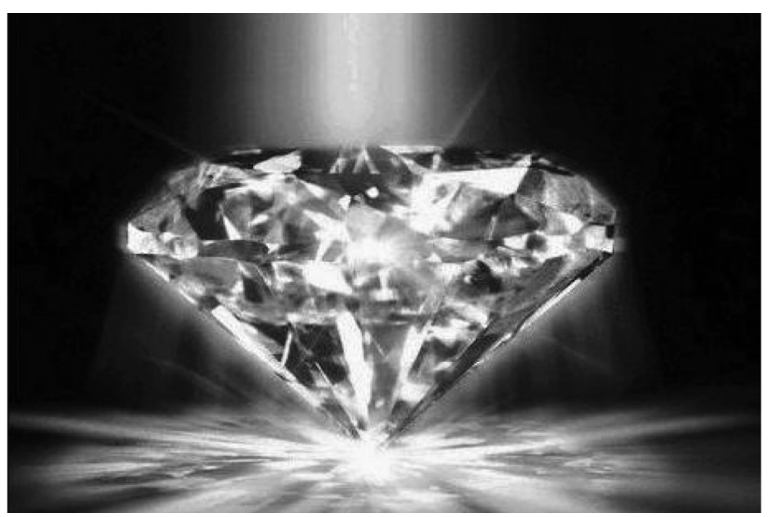

Fig. 15. Brilliant spectrum of diamond.

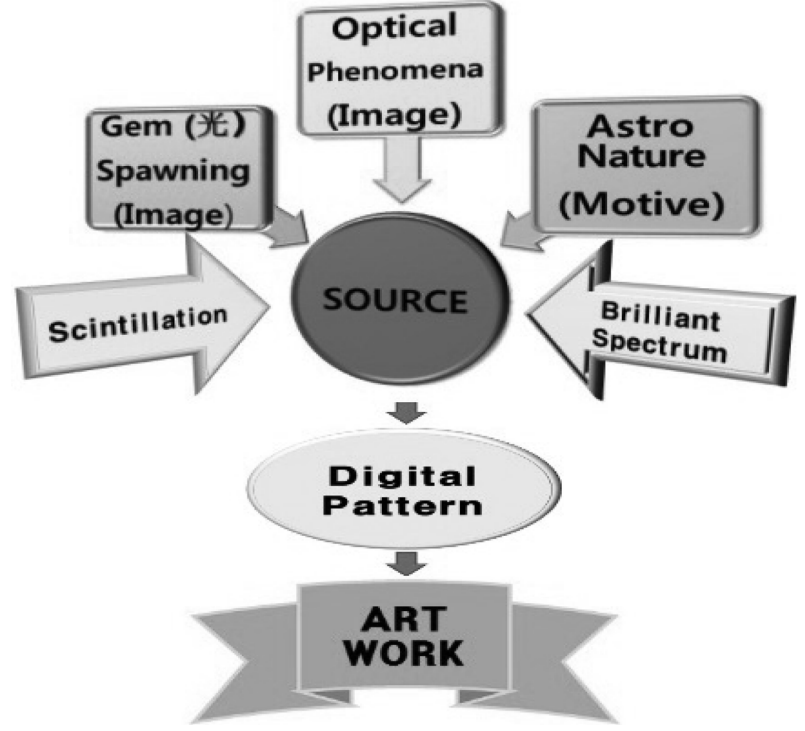

Fig. 16. Schematic diagram of design patterning process.

광산란 Image를 Source로 하였다. 상호 관련의 광학 현 상에 나타난 Bitmap Graphics Image를 Digital Pattern 으로 형성하여 보았다(Fig. 11-15).

\subsection{Design process}

Fig. 16은 천연 보석의 광산란 반응과 신비로움을 연 


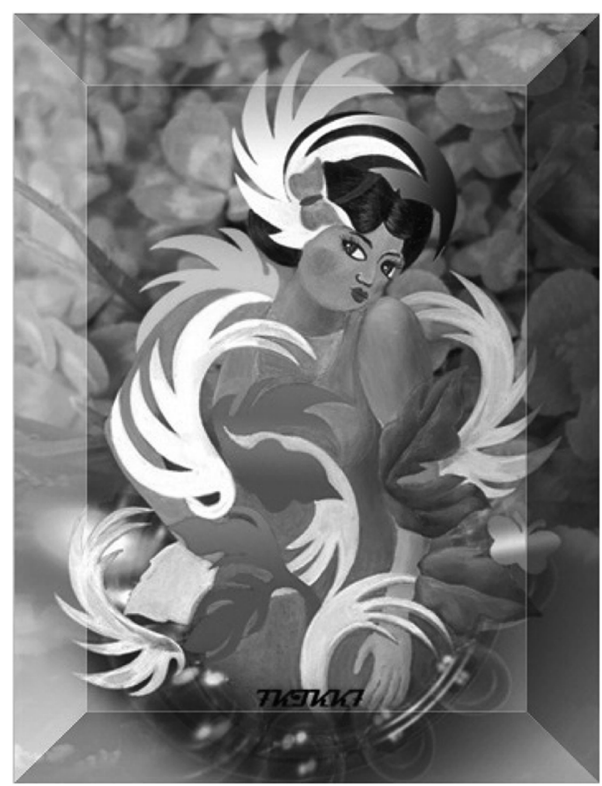

(a) Works 1

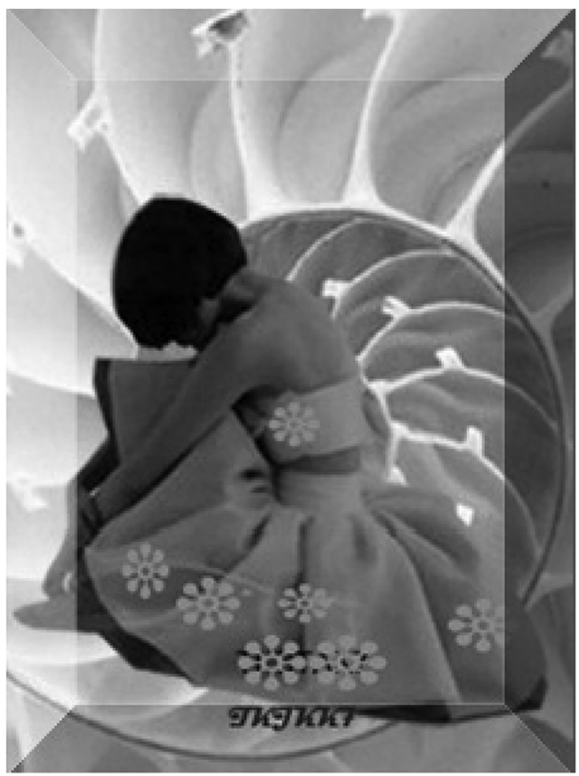

(b) Works 2

Fig. 17. Designed as an picture and photo images designed by author (a) Picture-Acrylic Painting <Works 1> (Motive: Golden dew) and (b) Photo-Digital Computer Graphic <Works 2> (Motive: Golden Ratio).

상케하는 현상을 Image Source로 하여, 디지털의 패턴 화 작업에서 요구되는 Art Work의 제작 과정을 보인 것 이며, Fig. 17(a, b)은 Fig. 16의 과정을 거쳐서 제작된 창작품을 나타낸 것이다. <Art Work.3>과 <Art Work.4> 는 제작된 작품 디자인이 적용된 실험적인 형태로서, Mural Art Wall에 적합한 Digital Pattern의 Design Modeling을 제시하였다.

Table 3과 Fig. 18은 Wall-Deco[12] 용도로 적합한 그 래픽 디자인의 개발과, 공간 조형 및 Design 과정을 개 략적으로 설명하였다. Color Image Scale 시스템(Fig. 18(a))과 Normal Color Wheel(Fig. 18(b)) 조명의 감성 분석에서, 벽면에 조형의 가변성과 역동성, 은유성, 연속 성을 표현하고자 하였다[13].

\section{IV. 결과 및 고찰}

Digital 패턴으로 형성된 <Works 1>과 <Works 2>는 Modeling의 디자인 요소로 적용하여, Fig. 19와 같이, <Art Work.1>과 <Art Work.2>를 완성하였다. Table 4 에서, 완성된 작품 <Art Work.1>과 <Art Work.2>의 상 세 Data를 작성하여 보였다.

위의 두 작품, <Art Work.1>과 <Art Work.2>는 천연 보석에서 나타나는 빛의 간섭 현상으로 조화를 이루고, 연관성에 대한 상호 작용이 서로 융합, 통일된 형태로 발현되었음을 알 수 있다.

Fig. 20에서, 빛은 색채와 반응하고 중심축으로 몰입 (Fig. 20(a)) 또는, 외부로 확산(Fig. 20(b))되는 효과를

Table 3

The procedure \& formative how of graphic designs and expression characteristics of interior space

\begin{tabular}{|c|c|c|c|}
\hline Menu (application) & Design development & \multicolumn{2}{|c|}{ Expression of the space } \\
\hline File & (1) Mode adjustments & \multirow{2}{*}{ Variance } & Light (immersion, diffusion) \\
\hline Edit & (2) Apply image & & Visualization of power \\
\hline Image (1) & (3) Image calculations & \multirow{2}{*}{ Dynamics } & Empathy \\
\hline Image (2) & (4) Pixel aspect ratio & & In the form of dynamic \\
\hline Layer & (5) Image reveal all & \multirow{2}{*}{ Metaphor } & Memories, experiences \\
\hline Select & (6) Image variables & & Sensory proximity, Similarity \\
\hline Filter & (7) Apply data set & \multirow{2}{*}{ Continuity } & Simulate associations \\
\hline View & (8) Artistic expression & & Activation of perceptual \\
\hline
\end{tabular}




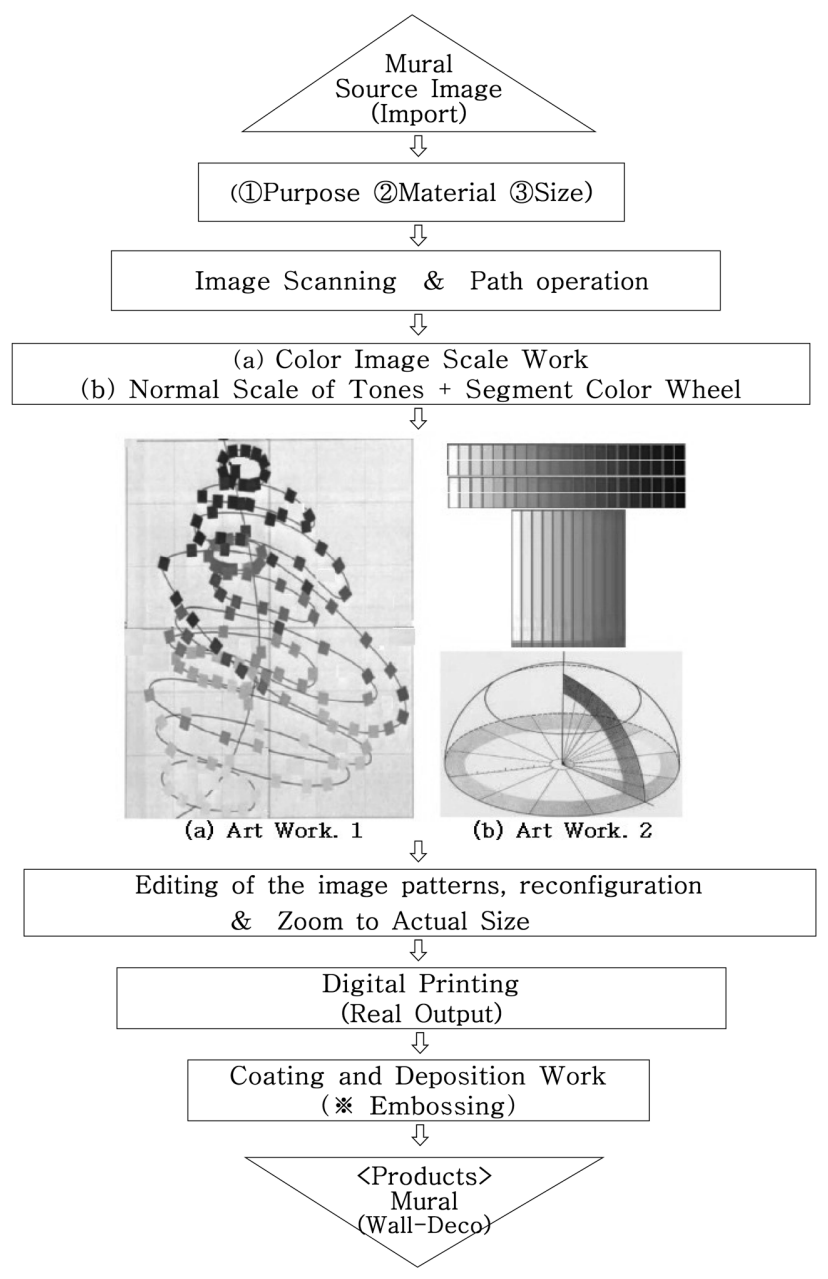

Fig. 18. Schematic flow chart of the (Mural) product design process.

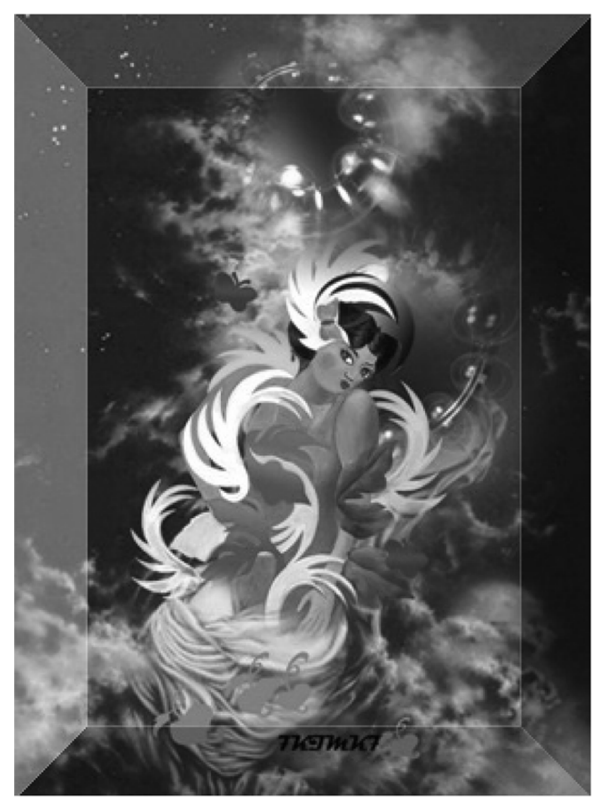

(a) Art Work. 1
실내의 형태나 구조에 대응하여 나타낸다. 광물을 연마 하여 패싯(Facet)으로 부터 나타나는 반짝임을 성채, 섬 광, 휘광 등의 광채로 표현할 수 있으며, 광채의 선명도 는 빛과 운동 방향의 원근감을 다르게 나타낸다. Table 3 에서 언급한 것처럼, 미학적으로 Golden $\operatorname{Ratio}(1: 1.6)$ 를 응용한 입체 표현과, 환영적 움직임을 공간에 나타내 는 투영 이미지로 전달되도록 한다(Fig. 20(C)). Fig. 19 의 작품에서, <Art Work.1>은 빛의 몰입과 진동 형상, <Art Work.2>는 배경, 매스(Mass), 표면 조직의 짜임새 와 결에 따라, 빛의 시각적 확산 효과가 다양하게 형성 될 수 있다.

\section{V. 결 론}

빛을 포함하는 천연 보석의 광채와 작품 디자인과의 연관성에 나타난 특징적 섬광, 휘광을 Digital(Mural) 패 턴으로 형성하고, 실물(<Art Work.1>, <Art Work.2>)이 적용된 Picture Frame의 Interior Modeling(<Art Work.3〉, <Art Work.4>)으로 완성하였다. 조형 표현의 방법을 확 대시키고자, 섬세한 색채와 다의성을 갖춘 디스플레이 (Display)는 구조적 배열의 예술적 가치를 높인다. 투명 성, 빛(자연의 변화), 인간의 움직임, 변화 가능성에 나타난 광학과 물리적 에너지의 조형 수단으로서 분석하 여 보고자 하였다. Fig. 21에서, <Art Work.3>과 <Art Work.4>의 작품 모델링을 통하여, 공간 작업에 나타난 장점을 활용하고, 자연물의 속성과 광학적 조형미를 벽

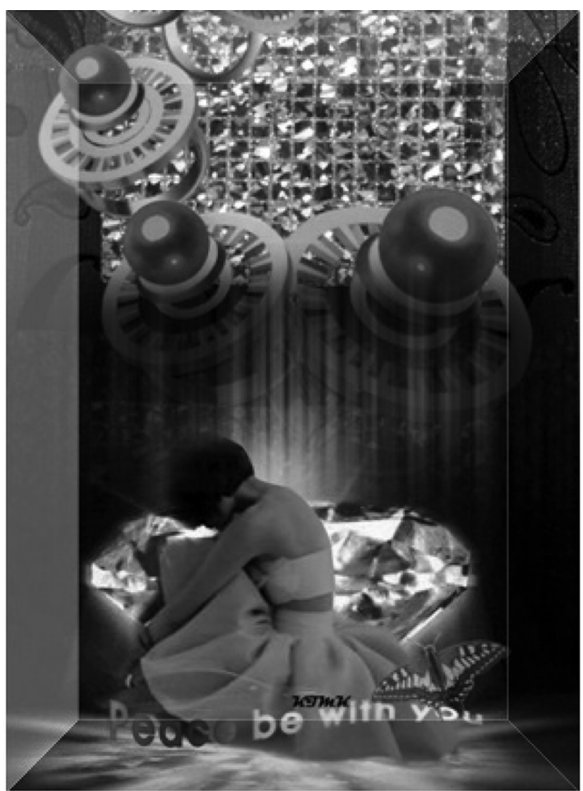

(b) Art Work. 2

Fig. 19. Designed art works (a) Graphic \& Acryil Painting (Title: Charisma) and (b) Digital Computer Graphic (Title: Grace of God). 
Table 4

Digital Artworks Data-Base, Art Work. 1 and Art Work. 2

\begin{tabular}{lll}
\hline Title & Charisma (Art Work. 1) & Grace of God (Art Work. 2) \\
\hline Theme & 'Vital Esprit' (ArtWork.1), 'Emotional Pastel' (ArtWork.2) \\
Materials & (laminated) Paper, PVC ( $\%$ Fabric) & \\
Original (file) size & $11.811 \times 17.929$ Pixels, $100 \mathrm{~cm} \times 161.8 \mathrm{~cm}$ & \\
Resolution & Bit depth (8 12), $300 \mathrm{dpi}$ & \\
Meta-data & Mode/RGB, Format/JPEG & \\
Pattern \& & (a) Mutual Immersion & (b) Mutual diffusion \\
image design & (1) Scintillation & (1) Dispersion \\
Year/section & (2) Giant Rolling (Blue) Jet & \\
\hline
\end{tabular}

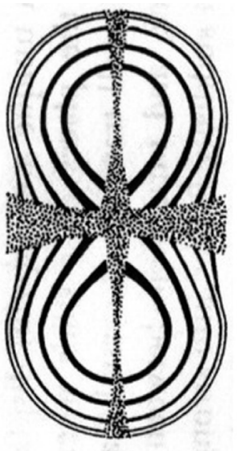

(a) Immersion

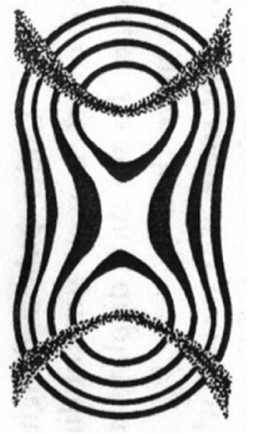

(b) Diffusion

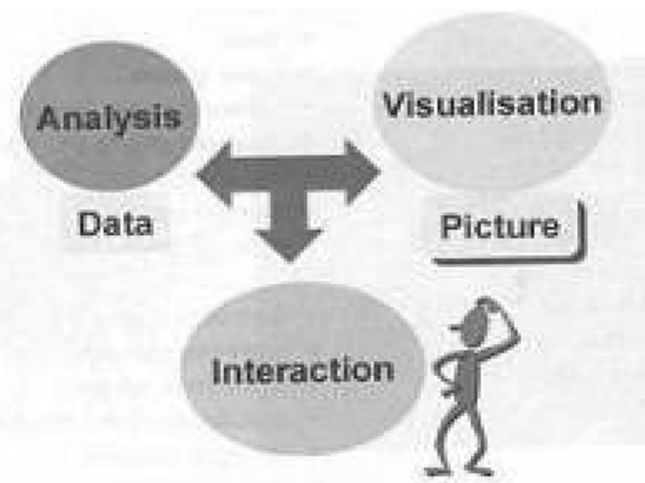

(c) Visualization of sensitivity

Fig. 20. Phenomenological response of light $(a, b)$ interact with the performance (c).

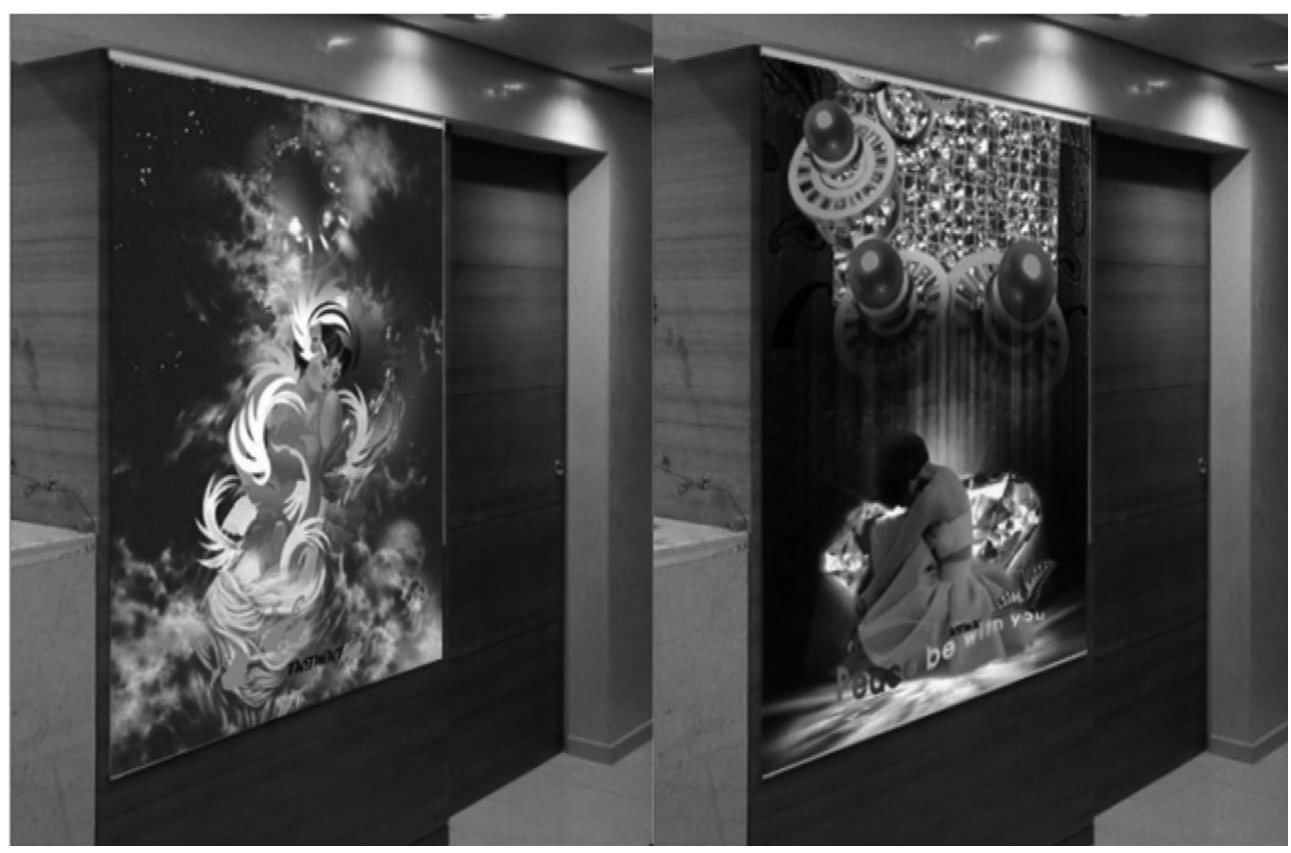

Fig. 21. Virtually designed (3D/Simulation) interior mural plastic modeling, Art Work.3 (Title: Charisma (left)) and Art Work.4 (Title: Grace of God (right)). 
면에 도입할 수 있는 고급 인테리어로의 디자인적 발전 이 기대된다.

\section{참 고 문 헌}

[1] L.A. Savoir, "Pattern Design" (Rockport, 2007) p.76.

[2] R.L. Boneuitz, "Rocks \& Minerals" (DK Publishing, United States, New York, 2008) p.87.

[ 3 ] C. Pellant, "Rocks and Minerals", 2nd ed. (DK Publishing, London, 2002) pp.18-31.

[4] H. Kuhn, H. Frsterling and David H. Waldeck, "Principles of Physical Chemistry" (A John Wiley \& Sons, Inc, publication, 2009) p.287.

[ 5 ] C. Jotisalikorn and K. Zabihi, "Color Spectrum" (Tut- tle, 2007) p.48.

[6] D. Stein, "GEM Stones A to Z" (Crossing Press, printed in Canada, 2008) p.98, 192, 148-150, 207, 183.

[7] K. Nassau, "Gems Made By Man", Gemological Institude of America (Santa Monica, California, 1886) p.75.

[ 8 ] M.L. Van, "500 Gemstone Jewels" (Lark Books, 2010) p.23.

[9] J. Harris and S. Withdraw, "Vector Graphics and Illusrtation" (Quayside, 2008) p.84.

[10] R. King, "Art" (DK Publishing, United States, New York, 2008) p.239.

[11] A. Grjffiths, "Simply Beautiful Photographs" (Focal Point China, 2010) p.40.

[12] G. James, "Creative Walls" (CICO Books, 2011) p.152.

[13] K. Ebben, "Wall Effects" (Conran, octopus, Printed in China, 2007) p.124. 